This is an electronic reprint of the original article. This reprint may differ from the original in pagination and typographic detail.

Author(s): Koivisto, Hannu; Kalvas, Taneli; Tarvainen, Olli; Komppula, Jani; Laulainen, Janne; Kronholm, Risto; Ranttila, Kimmo; Tuunanen, Juha; Thuillier, T.; Xie, D.; Machicoane, G.

Title: Ion source research and development at University of Jyväskylä: Studies of different plasma processes and towards the higher beam intensities

Year: $\quad 2016$

Version:

Please cite the original version:

Koivisto, H., Kalvas, T., Tarvainen, O., Komppula, J., Laulainen, J., Kronholm, R., Ranttila, K., Tuunanen, J., Thuillier, T., Xie, D., \& Machicoane, G. (2016). Ion source research and development at University of Jyväskylä: Studies of different plasma processes and towards the higher beam intensities. Review of Scientific Instruments, 87(2), Article 02A725. https://doi.org/10.1063/1.4934687

All material supplied via JYX is protected by copyright and other intellectual property rights, and duplication or sale of all or part of any of the repository collections is not permitted, except that material may be duplicated by you for your research use or educational purposes in electronic or print form. You must obtain permission for any other use. Electronic or print copies may not be offered, whether for sale or otherwise to anyone who is not an authorised user. 


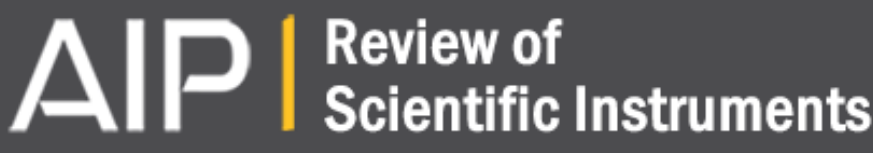

Ion source research and development at University of Jyväskylä: Studies of different plasma processes and towards the higher beam intensities

H. Koivisto, T. Kalvas, O. Tarvainen, J. Komppula, J. Laulainen, R. Kronholm, K. Ranttila, J. Tuunanen, T.

Thuillier, D. Xie, and G. Machicoane

Citation: Review of Scientific Instruments 87, 02A725 (2016); doi: 10.1063/1.4934687

View online: http://dx.doi.org/10.1063/1.4934687

View Table of Contents: http://scitation.aip.org/content/aip/journal/rsi/87/2?ver=pdfcov

Published by the AIP Publishing

Articles you may be interested in

Dynamics of ion beam charge neutralization by ferroelectric plasma sources

Phys. Plasmas 23, 043113 (2016); 10.1063/1.4947562

A gas-jet transport and catcher technique for on-line production of radioactive ion beams using an electron cyclotron resonance ion-source

Rev. Sci. Instrum. 84, 033301 (2013); 10.1063/1.4792594

Numerical study of the characteristics of the ion and fast atom beams in an end-Hall ion source J. Appl. Phys. 112, 083301 (2012); 10.1063/1.4759314

Effect of electron cyclotron resonance ion source frequency tuning on ion beam intensity and quality at Department of Physics, University of Jyväskyläa)

Rev. Sci. Instrum. 81, 02A319 (2010); 10.1063/1.3267287

High intensity beams from electron cyclotron resonance ion sources: A study of efficient extraction and transport system (invited)

Rev. Sci. Instrum. 75, 1637 (2004); 10.1063/1.1695647

\section{SHIMADZU Powerful, Multi-functional UV-Vis-NIR and} Excellence in Science FTIR Spectrophotometers

Providing the utmost in sensitivity, accuracy and resolution for applications in materials characterization and nano research

- Photovoltaics - Ceramics

- Polymers - DNA film structures

- Thin films $\quad$ Coatings

- Paints - Packaging materials

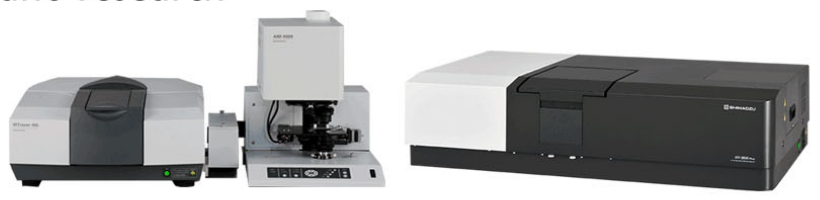




\title{
Ion source research and development at University of Jyväskylä: Studies of different plasma processes and towards the higher beam intensities
}

\author{
H. Koivisto, ${ }^{1, a)}$ T. Kalvas, ${ }^{1}$ O. Tarvainen, ${ }^{1}$ J. Komppula, ${ }^{1}$ J. Laulainen, ${ }^{1}$ R. Kronholm, ${ }^{1}$ \\ K. Ranttila, ${ }^{1}$ J. Tuunanen, ${ }^{1}$ T. Thuillier, ${ }^{2}$ D. Xie, ${ }^{3}$ and G. Machicoane ${ }^{4}$ \\ ${ }^{1}$ Department of Physics, University of Jyväskylä, P.O. Box 35 (YFL), FI-40014 Jyväskylä, Finland \\ ${ }^{2}$ LPSC, CNRS/IN2P3, Université Grenoble-Alpes1, 53 Rue des Martyrs, 38026 Grenoble Cedex, France \\ ${ }^{3}$ Lawrence Berkeley National Laboratory, One Cyclotron Road, Berkeley, California 94720, USA \\ ${ }^{4}$ National Superconducting Cyclotron Laboratory, Michigan State University, \\ East Lansing, Michigan 48824, USA
}

(Presented 24 August 2015; received 7 September 2015; accepted 13 October 2015; published online 11 November 2015)

\begin{abstract}
Several ion source related research and development projects are in progress at the Department of Physics, University of Jyväskylä (JYFL). The work can be divided into investigation of the ion source plasma and development of ion sources, ion beams, and diagnostics. The investigation covers the Electron Cyclotron Resonance Ion Source (ECRIS) plasma instabilities, vacuum ultraviolet (VUV) and visible light emission, photon induced electron emission, and the development of plasma diagnostics. The ion source development covers the work performed for radiofrequencydriven negative ion source, RADIS, beam line upgrade of the JYFL $14 \mathrm{GHz}$ ECRIS, and the development of a new room-temperature-magnet $18 \mathrm{GHz}$ ECRIS, HIISI. (C) 2015 AIP Publishing LLC. [http://dx.doi.org/10.1063/1.4934687]
\end{abstract}

\section{EXPERIMENTAL PLASMA RESEARCH}

Recent studies with the JYFL $14 \mathrm{GHz}$ ECRIS ${ }^{1}$ indicate that anisotropy of the electron energy distribution function (EEDF) related to ECR heating results in plasma instabilities associated with strong microwave emission and burst of energetic electrons limiting the intensity of the highest charge states. $^{2-4}$ The frequency and the amplitude of the instability event depend strongly on the magnetic field configuration, which limits the parameter space available for the production of the highest charge states. The experiments also suggest that the instabilities can be mitigated by 2 -frequency heating. ${ }^{5,6}$

An experimental setup has been developed to study plasma induced photoelectron emission from different plasma chamber materials. The experiments have shown that the effect could have a contribution to properties of hydrogen ion source plasma. Recent experiments with the JYFL $14 \mathrm{GHz}$ ECRIS have shown that the photon induced emission increases linearly with the microwave power and its maximum intensity can reach several milliamperes per kilowatt of microwave power injected into the ion source. Further experiments are needed to define its effect on plasma properties, such as plasma potential, and on the performance of ECR ion sources. For further details see Refs. 7 and 8.

A project to study the visible light emission of highly charged ECRIS plasma has been initiated. The objective is to measure the light intensity emitted by different charge states

Note: Contributed paper, published as part of the Proceedings of the 16th International Conference on Ion Sources, New York, New York, USA, August 2015.

a)hannu.koivisto@phys.jyu.fi in different operation conditions. The work will be performed first in the continuous wave (cw) operation mode by changing the ECRIS operation parameters such as microwave power and gas feeding rates. In the second step, the studies will focus on the transient plasma properties during the breakdown, also a short neutral gas pulse is introduced into the ECRIS plasma. The pulsing will be done using a fast gas-feeding valve developed for this purpose. The neutral gas pulse changes plasma conditions, which affects the charge state distribution and light emission of different charge states. The temporal behavior of ion beam intensities will be measured simultaneously with the light signals emitted by different charge states. This may reveal new information about the charge exchange process and about the electron energy distribution.

Figure 1 shows the visible light spectrum emitted by the argon plasma. The plasma was produced by the JYFL $14 \mathrm{GHz}$ ECRIS with an output microwave power of $50 \mathrm{~W}$ and 400 W. Most of the visible light emission originates from neutral argon atoms and $\mathrm{Ar}^{1+, 2+}$ ions. However, some highly charged ions also emit photons in visible light range. As an example, emission from neutral argon atom and $\mathrm{Ar}^{10+}$ ion has been identified in Fig. 1. As the figure shows, the light emission from $\mathrm{Ar}^{10+}$ is negligible at the microwave power of $50 \mathrm{~W}$ while its intensity is comparable with the emission from neutral argon at the microwave power of $400 \mathrm{~W}$. In the near future, the emissions from neutrals and different ions will be studied in different operation conditions. The relative changes of emitted signals will be recorded with the beam intensities in $\mathrm{cw}$ and pulsed operation mode and also when a short pulse of neutral gas is introduced into the plasma.

The VUV emission of filament-driven arc discharge and microwave discharge has been studied using optical filters and photodiodes. These developed diagnostics yield information, 


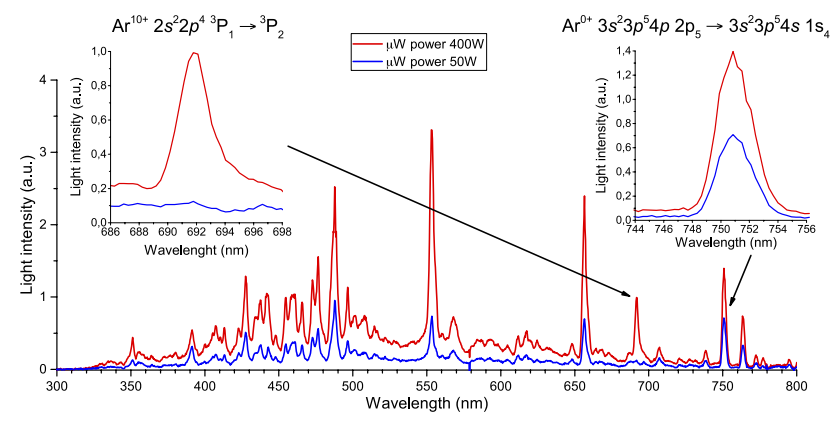

FIG. 1. Light signal measured from the argon plasma of the JYFL $14 \mathrm{GHz}$ ECRIS as a function of the wavelength.

for example, about the VUV emission power and different volumetric production rates. For further details see Refs. 9-13.

\section{DEVELOPMENT OF ION SOURCES AND THEIR BEAMS}

To meet the future requirements of the JYFL nuclear physics programs and to offer high quality research infrastructure, a major investment on the ion source and accelerator facilities is needed. At the end of 2013, the Academy of Finland funded the JYFL Accelerator Laboratory to design and construct an $18 \mathrm{GHz}$ ECR Heavy Ion Ion Source Injector (HIISI ${ }^{14,15}$ ). The physical design started at the beginning of 2014 and the engineering design of the main components was completed at the beginning of 2015. The main components for the generation of magnetic field will arrive by November 2015 and the first ion beam will be extracted by summer 2016 .

\section{A. Rearrangement of ion source area}

In order to have enough space for new $18 \mathrm{GHz}$ ECRIS, the filament driven $\mathrm{H}^{-}$ion source (called LIISA), ${ }^{16} 6.4 \mathrm{GHz}$ ECRIS, ${ }^{17}$ and $14 \mathrm{GHz}$ ECRIS have to be relocated. The JYFL $14 \mathrm{GHz}$ ECRIS was moved close to the $90^{\circ}$ bending magnet in May 2015. In the new location, the intermediate focal point of high charge states between the ion source and the mass separation is avoided, which possibly decreases the space charge problems experienced in this beam line section. At the same time, the entrance and exit angle of the dipole magnet were optimized in order to have the focal point in both transverse planes at the same distance. The $\mathrm{H}^{-}$ion source and $6.4 \mathrm{GHz}$ ECRIS will be moved to new location by the end of October 2015.

\section{B. RF driven ion source (RADIS) for negative light ions}

The RADIS RF (13.56 MHz) ion source is under development for replacing the filament-driven $\mathrm{H}^{-}$ion source of the MCC $30 / 15$ cyclotron. The main objective is to increase the mean time between maintenance works from a few days to months. The performance of RADIS has steadily increased and is approaching goal intensity level of $1 \mathrm{~mA} / \mathrm{kW}$ of $\mathrm{RF}$ power at the beam energy of $19 \mathrm{keV}$ (achieved: $0.7 \mathrm{~mA} /$ $1 \mathrm{~kW} / 6 \mathrm{~mm}$ extraction aperture). For further details see Refs. 18 and 19.

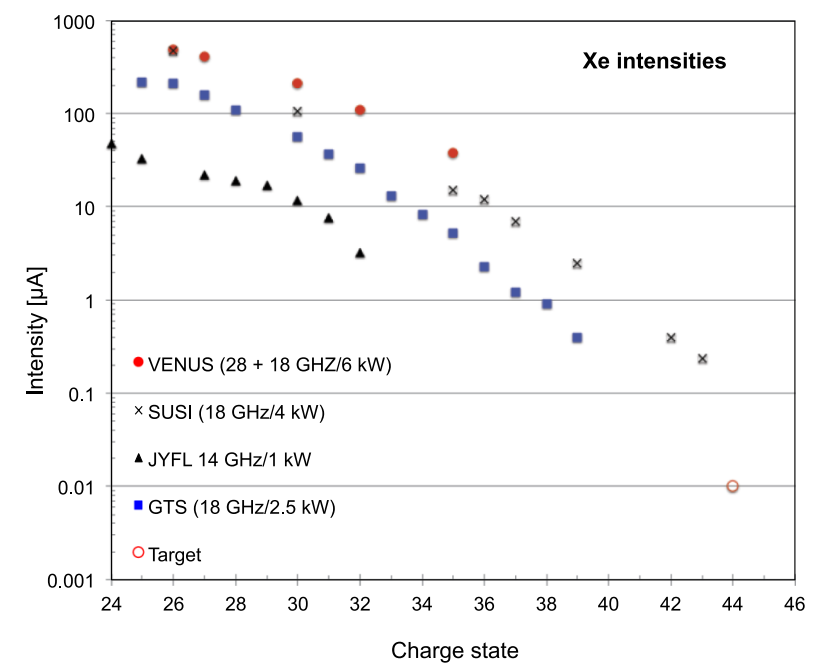

FIG. 2. Intensities of Xe ion beams produced by different ECR ion sources. The red circle indicates the beam intensity of $\mathrm{Xe}^{44+}$ ion beam to be produced with the new ECRIS operated at $18 \mathrm{GHz}$.

\section{HIISI: $18 \mathrm{GHz}$ ECRIS for the K130 cyclotron}

The objective of HIISI is to produce intense, medium charge state ion beams, such as $\operatorname{Ar}^{8+}(\mathrm{M} / \mathrm{q} \approx 5, \mathrm{E} \approx 5 \mathrm{MeV} / \mathrm{u})$. However, a very challenging requirement is also set by the research programs demanding highly charged, high-energy heavy ion beams $(\mathrm{M}>100, \mathrm{E}>15 \mathrm{MeV} / \mathrm{u})$. As an example, about $1 \mathrm{nA}$ of accelerated $\mathrm{Xe}^{44+}$ ion beam is needed for the program. This corresponds to at least $10 \mathrm{nA}$ of extracted ion beam from the ECRIS. Figure 2 shows the xenon ion beam intensities extracted from various well performing ECR ion sources. The requested ion beam is denoted by a red circle. The performance requirement can be met by 3rd generation ECR ion source such as VENUS and SUSI. ${ }^{20,21}$ In the case of SUSI, the presented intensities were achieved by using $18 \mathrm{GHz}$ operation frequency. More importantly, the same SUSI magnetic field configuration can be produced with room temperature magnets and this is the design base for HIISI.

Table I shows the magnetic field configuration of SUSI when it has been tuned for the production of highly charged xenon ion beams using $18 \mathrm{GHz}$ operation frequency. The table shows also the magnetic field configuration of HIISI confirming that the axial magnetic field strength needed for efficient operation at $18 \mathrm{GHz}$ can be met. The plasma chamber of both ion sources is $100 \mathrm{~mm}$ in diameter. Relatively large plasma chamber volume together with a high axial magnetic field requirement $\left(\mathrm{B}_{\text {inj }}=2.7 \mathrm{~T}\right.$ and $\left.\mathrm{B}_{\text {ext }}=1.5 \mathrm{~T}\right)$ results in a power consumption of about $210 \mathrm{~kW}$ for HIISI. Decreasing the extraction field from about $1.5 \mathrm{~T}$ to $1.3 \mathrm{~T}$,

TABLE I. The magnetic field configuration of SUSI optimized for the production of $\mathrm{Xe}^{35+}$ ion beam. This configuration has been used for the design goal of HIISI.

\begin{tabular}{lccc}
\hline \hline ECRIS & $\mathrm{B}_{\text {Inj/Min } / \text { Ext } / \text { Rad }}(\mathrm{T})$ & $\nabla \mathrm{B}_{\text {Inj/Ext }}(\mathrm{T} / \mathrm{m})$ & $\mathrm{L}(\mathrm{mm})$ \\
\hline SUSI & $2.8 / 0.46 / 1.56 / 1.36$ & $6.6 / 5.9$ & 115 \\
HIISI & $2.7 / 0.43 / 1.52 / 1.30$ & $6.3 / 6.3$ & 132 \\
\hline
\end{tabular}


i.e., close to $B_{\text {rad }}$, should reduce the power consumption to about $150 \mathrm{~kW}$.

The experimental data and simulations ${ }^{22}$ suggest that low magnetic field gradient at resonance results in efficient electron heating and consequently anisotropic velocity distribution. The anisotropy results in unstable plasma behavior being detrimental especially for the production of highly charged ions. Because of this concern, the gradient of axial magnetic field was used as one design parameter of HIISI. As the table shows, the gradients of the axial magnetic field of SUSI and HIISI are practically identical. The plasma length L of HIISI slightly exceeds the plasma length of SUSI. Here, the plasma length L is the distance between the axial resonance points for the nonrelativistic electrons.

As Table I shows, the radial magnetic field $\mathrm{B}_{\mathrm{rad}}$ was $1.36 \mathrm{~T}$ when SUSI was tuned for the production of highly charged xenon ion beams. This magnetic field value is very difficult to achieve by using permanent magnets. However, the properties of permanent magnet, such as remanence magnetic field $B_{\text {rem }}$ and coercive force $\mathrm{H}_{\mathrm{ci}}$, improve when the temperature of the magnet decreases. The lower temperature allows the use of magnet grade with a high $\mathrm{B}_{\text {rem }}$ thanks to the $\mathrm{H}_{\mathrm{ci}}$ increase, leading to a higher sextupole magnetic field at the plasma chamber wall.

This low temperature induced property improvement is exploited in HIISI to maximize the radial magnetic field $\left(\mathrm{B}_{\mathrm{rad}}\right)$. The permanent magnet multipole will be vacuum insulated from the surrounding structures, especially from the plasma chamber, to ensure efficient cooling of the permanent magnets. The objective is to operate the permanent magnets close to $-20^{\circ} \mathrm{C}$, which would increase the coercivity force approximately by $50 \%$ when compared to room temperature. The structure also allows to keep the distance between the inner surface of the plasma chamber and the permanent magnet below the typical value of $5 \mathrm{~mm}$. This distance has to be minimized in order to maximize the value of $\mathrm{B}_{\mathrm{rad}}$ at the plasma chamber wall.

The main heat load on the vacuum insulated permanent magnet blocks comes from the heat transfer by the residual molecules inside the vacuum gap and by the heat radiation. The conductive heat load through the insulated support structures is negligible. The sextupole chamber has a dedicated cooling circuit, which makes it possible to keep the magnets below the freezing point. Such a design with improved coercivity of the permanent magnets offers a good safety margin against the demagnetization and also allows the use of stronger magnet grade (in terms of $\mathrm{B}_{\text {rem}}$ ). Comprehensive heat load simulations have been presented in Ref. 15.

The nominal values of the permanent magnet grade selected for HIISI at $20^{\circ} \mathrm{C}$ are $\mathrm{B}_{\text {rem }}=1.33 \mathrm{~T}$ and $\mathrm{H}_{\mathrm{ci}}=1595 \mathrm{kA} / \mathrm{m}$. Figure 3 shows the demagnetization analysis when the solenoids are excited to produce $\mathrm{B}_{\mathrm{inj}}$ and $\mathrm{B}_{\text {ext }}$ values listed in Table I. The analysis indicates that inside the most critical magnet volume the demagnetizing field is close to the maximum value the permanent magnet can withstand. Consequently, it is of great importance that the permanent magnets are kept below room temperature and their temperature is monitored. The different heat expansion coefficient in perpendicular and parallel direction with respect to the magnetization

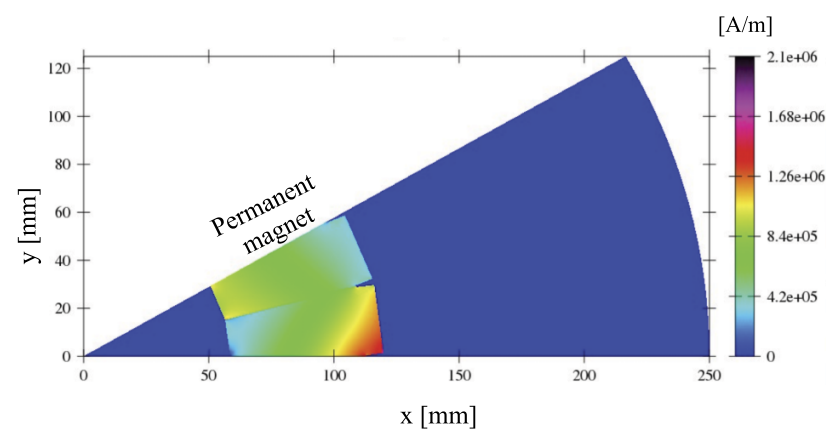

FIG. 3. Demagnetization analysis of HIISI permanent magnets. The nominal axial magnetic field listed in Table I has been used in simulations.

vector might cause some technical challenges but the final objective is to reach a safe operation condition below the freezing point (close to $-20^{\circ} \mathrm{C}$ ). This would allow the use of stronger permanent magnets and thus to reach a radial magnetic field of about $1.4 \mathrm{~T}$.

Figure 4 shows the structure of the plasma and sextupole chambers. Careful considerations and simulations were performed in order to maximize the heat transfer from the aluminum plasma chamber to cooling water. Thermal simulations indicate the plasma chamber should withstand input microwave power up to $5 \mathrm{~kW}$. At this power, the peak temperature of plasma chamber, corresponding to the highest plasma flux area, is slightly above $100^{\circ} \mathrm{C}$ which is close to the maximum safe operation temperature of an aluminum plasma chamber.

Figure 5 shows the cross section of the JYFL $18 \mathrm{GHz}$ ECRIS. Its minimum-B field strength supports plasma heating frequency of $14.5 \mathrm{GHz}$ and $18 \mathrm{GHz}$ simultaneously. In

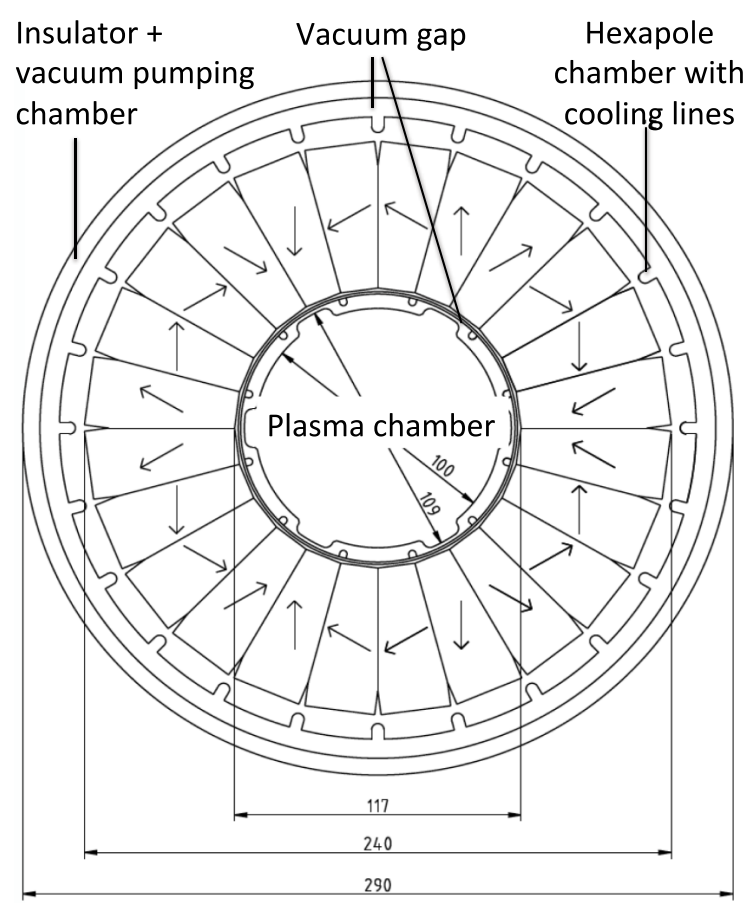

FIG. 4. The HIISI plasma chamber and its cooling lines, permanent magnets are assembled inside the vacuum insulated sextupole chamber. Sextupole chamber is inside the vacuum pumping chamber. 


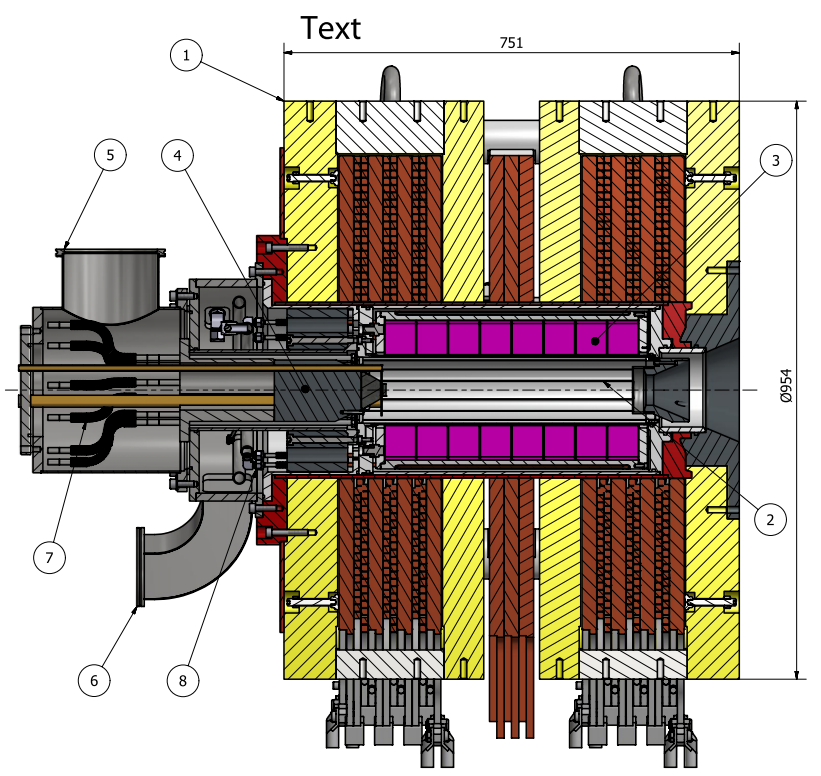

FIG. 5. The JYFL 18 GHz ECRIS: HIISI. (1) Yoke and solenoid structure, (2) plasma chamber, (3) permanent magnet sextupole, (4) injection low carbon steel/permendur plug, (5) injection pumping, (6) pumping of sextupole vacuum chamber, (7) cooling of the plasma chamber, (8) cooling for the permanent magnets (allows the cooling down to $-20^{\circ} \mathrm{C}$ ).

addition, the plasma can be heated using two independent heating frequencies between 14.5 and $18 \mathrm{GHz}$ making 4frequency heating possible. The fourth frequency may offer further improvement especially in the case of the highest charge states. ${ }^{23}$

\section{ACKNOWLEDGMENTS}

This work has been supported by the EU 7th frame-work program Integrating Activities-Transnational Access, Project No. 262010 (ENSAR), and the Academy of Finland under the Finnish Centre of Excellence Program 2012-2017 (Nuclear and Accelerator Based Physics Research at JYFL).

${ }^{1}$ H. Koivisto, P. Heikkinen, V. Hänninen, A. Lassila, H. Leinonen, V. Nieminen, J. Pakarinen, K. Ranttila, J. Ärje, and E. Liukkonen, Nucl. Instrum. Methods Phys. Res., Sect. B 174, 379 (2001).
${ }^{2}$ O. Tarvainen, I. Izotov, D. Mansfeld, V. Skalyga, S. Golubev, T. Kalvas, H. Koivisto, J. Komppula, R. Kronholm, J. Laulainen, and V. Toivanen, Plasma Sources Sci. Technol. 23, 025020 (2014).

${ }^{3}$ I. Izotov, O. Tarvainen, D. Mansfeld, V. Skalyga, H. Koivisto, T. Kalvas, J. Komppula, R. Kronholm, and J. Laulainen, Plasma Sources Sci. Technol. 24, 045017 (2015).

${ }^{4} \mathrm{O}$. Tarvainen et al., "Limitation of the ECRIS performance by kinetic plasma instabilities," Rev. Sci. Instrum. 87, 02 A703 (2016).

${ }^{5}$ Z. Q. Xie and C. M. Lyneis, Rev. Sci. Instrum. 66, 4218 (1995).

${ }^{6}$ V. Skalyga et al., Phys. Plasmas 22, 083509 (2015).

${ }^{7}$ J. Laulainen, T. Kalvas, H. Koivisto, J. Komppula, and O. Tarvainen, AIP Conf. Proc. 1655, 020007 (2015).

${ }^{8}$ J. Laulainen, T. Kalvas, H. Koivisto, J. Komppula, R. Kronholm, and O. Tarvainen, Rev. Sci. Instrum. 87, 02 A506 (2016).

${ }^{9}$ J. Komppula, O. Tarvainen, S. Lätti, T. Kalvas, H. Koivisto, V. Toivanen, and P. Myllyperkiö, "Third international symposium on negative ions, beams and sources (NIBS 2012) 3-7 Sept. (2012), Jyväskylä, Finland,” AIP Conf. Proc. 1515, 66 (2013).

${ }^{10}$ J. Komppula, O. Tarvainen, T. Kalvas, H. Koivisto, R. Kronholm, J. Laulainen, and P. Myllyperkiö, J. Phys. D: Appl. Phys. 48, 365201 (2015).

${ }^{11}$ J. Komppula and O. Tarvainen, Plasma Sources Sci. Technol. 24, 045008 (2015).

${ }^{12}$ J. Komppula, Ph.D. thesis, JYFL Research Report, November 2015 (to be published).

${ }^{13}$ J. Komppula, T. Kalvas, H. Koivisto, R. Kronholm, J. Laulainen, and O. Tarvainen, "VUV-diagnostics of inelastic collision processes in low temperature hydrogen plasmas," in Proceedings of the 16th International Conference on Ion Sources, New York, 2015.

${ }^{14}$ H. Koivisto et al., ECRIS14: JACOW, Nizhny Novgorod, Russia, 2014, TUOMMH05.

${ }^{15}$ T. Kalvas, O. Tarvainen, H. Koivisto, and K. Ranttila, ECRIS14: JACOW, Nizhny Novgorod, Russia, 2014, WEOMMH04.

${ }^{16}$ T. Kuo, R. Baartman, G. Dutto, S. Hahto, J. Ärje, and E. Liukkonen, Rev. Sci. Instrum. 83, 02A727 (2012).

${ }^{17}$ H. Koivisto, P. Heikkinen, E. Liukkonen, J. Ärje, and R. Vondrasek, "Low cost upgrade of $6.4 \mathrm{GHz}$ ECRIS and recent results with $14 \mathrm{GHz}$ ECRIS at JYFL,” Rev. Sci. Instrum. 73(2), 534 (2002).

${ }^{18}$ T. Kalvas, O. Tarvainen, J. Komppula, H. Koivisto, J. Tuunanen, D. Potkins, T. Stewart, and M. P. Dehnel, "Fourth international symposium on negative ions, beams and sources (NIBS 2014) 6-10 Oct. (2014), Garching, Germany," AIP Conf. Proc. 1655, 030015 (2015).

${ }^{19}$ T. Kalvas, O. Tarvainen, J. Komppula, H. Koivisto, J. Tuunanen, D. Potkins, T. Stewart, and M. Dehnel, "Power efficiency improvements with the radiofrequency $\mathrm{H}^{-}$ion source," Rev. Sci. Instrum. 87, 02B102 (2016).

${ }^{20}$ C. M. Lyneis, D. Leitner, S. R. Abbott, R. D. Dwinell, M. Leitner, C. S. Silver, and C. Taylor, Rev. Sci. Instrum. 75(5), 1389 (2004).

${ }^{21}$ P. A. Zavodszky et al., Rev. Sci. Instrum. 79, 02 A302 (2008).

${ }^{22}$ H. Koivisto, Rev. Sci. Instrum. 70(7), 2979 (1999).

${ }^{23}$ H. Koivisto, P. Suominen, O. Tarvainen, A. Virtanen, and A. Parkkinen, Rev. Sci. Instrum. 77, 03A316 (2006). 